Ensino, Saúde e Ambiente-V5 (2), pp. 246-257, ago. 2012

\title{
AS ABORDAGENS DOS CONTEÚDOS DE QUÍMICA NO JOGO DIDÁTICO DENOMINADO "JOGO DAS ÁGUAS"
}

\section{THE APPROACHES OF CHEMICAL CONTENTS IN A GAME EDUCATIONAL CALLED “JOGO DAS ÁGUAS”}

\author{
Fátima de Paiva Canesin ${ }^{1,2}$; Rose Mary Latini ${ }^{1,2}$; Maria Bernadete Pinto dos Santos ${ }^{1,2}$; \\ Lucidea R. Coutinho ${ }^{1,2}$ e Alfredo Victor Bellido Bernedo ${ }^{1}$ \\ ${ }^{1}$ Universidade Federal Fluminense/Departamento de Físico-Química \\ ${ }^{2}$ Universidade Federal Fluminense/Mestrado Profissional em Ensino de Ciências da Natureza \\ fatimacanesin@yahoo.com.br; rmlatini@uol.com.br, mbpsantos@gmail.com; lucideac@yahoo.com.br; \\ alfredobellido@gmail.com
}

\section{RESUMO}

O objetivo deste trabalho foi analisar o conteúdo de um jogo didático, denominado "Jogo das Águas", disponível no Banco Internacional de Objetos Educacionais, considerando os conteúdos de Química e suas articulações com situações cotidianas, implicações tecnológicas, sociais e ambientais. Trata-se de uma pesquisa qualitativa, de cunho interpretativo, cujos dados foram os textos presentes nas cartas do jogo. As categorias de análise Química; Educação Ambiental; Química e Cotidiano; Química e Meio Ambiente e Química e CTS foram identificadas pela análise textual discursiva. Os resultados apontam que a articulação de conhecimentos não está presente nas duas primeiras categorias e, que nas outras, a articulação permite que o professor introduza novas linguagens no ensino de química, favorecendo o aprendizado de forma mais integrada.

Palavras-chave: Ensino de Química, Jogo Didático, Ciência-Tecnologia-Sociedade.

\section{ABSTRACT}

This study had as objective to analyze the content of an educational game, called " Jogo das Águas", available on the "Banco Internacional de Objetos Educacionais", considering its chemistry's content, link to everyday situations, and technological, social and environmental implications. It is a qualitative research, of interpretive nature, whose data was present in the texts of the game.The following categories were identified by textual analyses: Chemistry, Environmental Education, Everyday Chemistry, Chemistry and Environment, and Chemistry and its relation to Technology, Society and Environment. The results show that the articulation of knowledge is not present in the first two categories and, in the others, the articulation allows the teacher to introduce new ways in teaching chemistry, favoring the learning process in a more integrate way

Key words: Teaching Chemistry, Educational Game, Science-Technology-Society

\section{INTRODUÇÃO}

O ensino-aprendizagem de Ciências/Química tem sido evidenciado, em vários trabalhos, como sendo marcado por estratégias de transmissão e memorização de conteúdos ou, então, com o objetivo apenas de aumentar o conhecimento dos alunos a respeito de fenômenos. Tais estratégias desconsideram a Ciência como uma construção 
histórica e social e impedem o estabelecimento de sua relação com o avanço tecnológico e as implicações decorrentes deste para a sociedade.

De acordo com as Orientações Curriculares para o Ensino Médio, na área de Ciências da Natureza, Matemática e suas Tecnologias (BRASIL, 2006, p.107), entendese que,

...de forma geral, o ensino praticado nas escolas não está propiciando ao aluno um aprendizado que possibilite a compreensão dos processos químicos em si e a construção de um conhecimento químico em estreita ligação com o meio cultural e natural, em todas as suas dimensões, com implicações ambientais, sociais, econômicas, ético-políticas, cientí cas e tecnológicas.

Entretanto, nos últimos 20 anos, membros da comunidade de educadores químicos têm contribuído com propostas alternativas a esse modelo tradicional de ensino (SCHNETZLER, 2010), as quais vão ao encontro da proposta apresentada para o ensino de Química nos PCN+, os quais

\begin{abstract}
...se contrapõe à velha ênfase na memorização de informações, nomes, fórmulas e conhecimentos como fragmentos desligados da realidade dos alunos. Ao contrário disso, pretende que o aluno reconheça e compreenda, de forma integrada e signi cativa, as transformações químicas que ocorrem nos processos naturais e tecnológicos em diferentes contextos, encontrados na atmosfera, hidrosfera, litosfera e biosfera, e suas relações com os sistemas produtivo, industrial e agrícola. (BRASIL, 2002, p.87).
\end{abstract}

Tais propostas vão também ao encontro do movimento CTS (CiênciaTecnologia e Sociedade), que desde o final da década de 70, defende a inclusão destas relações nos cursos de ciências da natureza em função das implicações da ciência e tecnologia para a vida das pessoas (SCHNETZLER, 2004). Ainda de acordo com a mesma autora a inserção de tal proposta visa, "a necessidade dos alunos adquirirem conhecimentos científicos que os levem a participar como cidadãos na sociedade, de forma ativa e crítica, pela tomada de decisões" (p.52).

Dentre as implicações do avanço científico e tecnológico, talvez, a de maior repercussão social seja o impacto ambiental. Problemas como escassez e poluição de água, aquecimento global, consumismo, excesso de produção de lixo, miséria entre outros são temas recorrentes. Mas, embora recorrentes, a pouca ou nenhuma compreensão dos fenômenos relacionados pode agravar ainda mais a crise ambiental. Concordamos com Guimarães e Vasconcellos (2006, p.153), quando estes apontam que 
"para discutir e se engajar como cidadão no enfrentamento dos problemas socioambientais, a população precisa estar cientificamente alfabetizada, politicamente consciente e engajada".

De um modo geral, observamos que os livros didáticos e alguns objetos educacionais disponíveis para o ensino de Química (BRASIL, 2008) quando se propõem discutir questões ambientais estão centrados na problemática socioambiental ou, então, estão focados no conteúdo químico propriamente dito, deixando de articular os conhecimentos oriundos das duas áreas. Na maioria das vezes, nos livros didáticos, esta articulação só acontece quando se trata do conteúdo de óxidos. Neste ponto as interações de óxidos na atmosfera e as conseqüências para a sociedade ganham destaque.

Com os avanços tecnológicos na área de informática a presença e a utilização de computadores e internet no ambiente escolar já é possível em muitas escolas, possibilitando implementar ambientes de ensino-aprendizagem de forma contextualizada. Diferentes recursos midiáticos são desenvolvidos como nova ferramenta pedagógica.

De acordo com Krasylchik (2000), o jogo didático no computador surge como uma tendência para o ensino de ciências neste período de globalização. Este como recurso pedagógico permite o desenvolvimento de competências e habilidades (KISHIMOTO, 2002; OLIVEIRA e SOARES, 2005; SOARES e CAVALHEIRO, 2006). Para Vigotski (2003, p.107), a importância das regras do jogo consiste em que,

.....ao subordinar todo o comportamento a certas regras convencionais, ele é o primeiro a ensinar uma conduta racional e consciente. Para a criança, o jogo é a primeira escola de pensamento. Todo pensamento surge como resposta a um problema, como resultado de um novo ou difícil contato com os elementos do meio.... Em outras palavras, o jogo [com regras] é um sistema racional e adequado, planejado, coordenado socialmente, subordinado a certas regras.

Assim, a construção do conhecimento a partir de uma atividade lúdica, como um jogo, com propósitos educacionais permite que o conteúdo didático seja apresentado de modo não formal e o desafio de vencer os obstáculos possibilita ao aluno-jogador a fixação dos conceitos já aprendidos, a interdisciplinaridade, a socialização e o trabalho de equipe, além da construção do seu próprio conhecimento.

No Banco Internacional de Objetos Educacionais (BRASIL, 2008) estão disponíveis vários objetos educacionais de acesso público para todos os níveis de 
ensino, dentre eles, os jogos computacionais. Na área de Química estes estão disponíveis com o título "Jogo" nas seguintes classes de objetos: Animação/Simulação e Softwares Educacionais. Em Animação/Simulação estão disponíveis os jogos intitulados “Jogo da Radiação e Jogo das Águas" e, em Softwares Educacionais, os jogos "Jogo da Descoberta dos Pares, Jogo das Coisas, Jogo dos Elementos 1 e Jogo dos Elementos 2".

Como objeto de estudo deste trabalho escolhemos o jogo intitulado "Jogo das Águas" já que o tema permite explorar as propriedades dessa substância, em diferentes conteúdos do ensino de Química, contextualizada com situações tecnológicas, cotidianas e socioambientais, conforme sugerida nos documentos atuais.

Assim, o objetivo deste trabalho foi analisar o conteúdo do "Jogo das Águas" considerando os conteúdos de Química e suas articulações com situações cotidianas, implicações tecnológicas, sociais e ambientais visando conhecer como este pode ser utilizado como recurso didático para o professor que deseje trabalhar de acordo com as propostas de ensino contidas nos documentos oficiais.

\section{DESCRIÇÃO DO JOGO DAS ÁGUAS}

O Jogo das Águas ${ }^{1}$ é um jogo do tipo tabuleiro desenvolvido em três fases, o objetivo é avançar nas casas percorrendo a trilha até o fim. A trilha é dividida em casas brancas, verdes e vermelhas. As cartas brancas indicam movimentação no pino no tabuleiro e não possuem conteúdo; as verdes são constituídas de 45 perguntas objetivas e, as vermelhas, 31 informações temáticas divididas nas três fases do jogo. Para se avançar nas casas o aluno aciona uma roleta com o mouse e um pino colorido se move. Se a roleta parar na casa verde, abre-se uma janela com uma pergunta objetiva com o tema água. As perguntas são formuladas com três opções de respostas. O jogador com o auxílio do mouse, marca a mesma. Se o jogador acertar a resposta ele anda uma casa no tabuleiro ou não se move se errou a resposta. Caso a roleta pare na cor vermelha, abrese uma janela com uma informação sobre a água. Quando o pino está numa casa vermelha o jogador não se move no tabuleiro. Se a roleta parar na cor branca, esta representa um bônus e o jogador avança no tabuleiro o número de casas indicadas, variando de 1 a 6. Quando o jogador completar o percurso do tabuleiro ou responder todas as cartas verdes ele passa para a fase seguinte. Vence o jogo o jogador que

\footnotetext{
${ }^{1}$ Disponível em http://objetoseducacionais2.mec.gov.br/handle/mec/15603
} 
responder corretamente o maior número de questões. $\mathrm{Na}$ tela inicial do jogo são apresentadas as instruções do mesmo. O jogo pode ser aplicado para no máximo quatro jogadores por computador e cada jogador deve, com o auxílio da roleta, definir a ordem de jogada de cada participante. O tempo estimado para percorre a trilha completa é de 50 minutos com quatro jogadores. Este tempo é reduzido se o número de jogadores for menor.

De acordo com o Guia do Professor, disponível juntamente com o jogo, os objetivos do mesmo são: perceber que a água é fundamental para a sobrevivência dos seres vivos e está presente no cotidiano, estabelecer relação entre as propriedades da água e a visão da água como recurso hídrico esgotável e sujeito a degradação e contribuir para a melhoria da percepção ambiental e da compreensão de conceitos abstratos.

\section{ENCAMINHAMENTOS METODOLÓGICOS}

Utilizamos a pesquisa qualitativa pela possibilidade de interpretar dados a partir de significados e concepções presentes nos textos contidos nas cartas do jogo (LÜDKE e ANDRÉ, 1986). O acesso ao conteúdo das cartas foi feito a partir de rotinas disponíveis no próprio endereço do jogo, e não jogando on line, pois durante o jogo as cartas surgem na tela de forma aleatória.

A análise dos dados foi feita pela análise textual discursiva de acordo com Moraes (2003). Segundo ele "toda análise textual concretiza-se a partir de um conjunto de documentos denominado corpus. Esse conjunto representa as informações da pesquisa e para a obtenção de resultados válidos e confiáveis, requer uma seleção e delimitação rigorosa" (op cit, p.10).

Assim, iniciamos a leitura das cartas com dois objetivos. O primeiro de identificar quais os conteúdos de químicas do currículo do ensino médio foram abordados em cada uma das fases do jogo. E, o segundo objetivo foi identificar a apresentação do conteúdo de Química, isto é, se este estava ou não associado com situações cotidianas, implicações tecnológicas, sociais e ambientais. Foram então lidos os conteúdos de todas as cartas verdes, que foram sendo separadas a partir da identificação de elementos com características comuns ou relacionados entre si no conteúdo das mesmas. $\mathrm{O}$ mesmo procedimento foi adotado para as cartas vermelhas. 


\section{A ANÁLISE DO CONTEÚdO DE QUÍMICA NO JOGO DAS ÁGUAS}

As perguntas ou proposições presentes nas cartas tinham como objetivo testar o conhecimento químico do aluno, verificar se ele sabe aplicar este conhecimento a uma dada situação (cartas verdes) ou apenas informar a respeito de propriedades da água visando à reflexão do aluno sobre o seu uso (cartas vermelhas). Algumas vezes, uma mesma carta apresentava mais de um conteúdo de Química necessário para responder a pergunta ou compreender uma dada situação proposta.

Os conteúdos de Química identificados no jogo são apresentados na Tabela 1. Esses estão concentrados nas cartas verdes e nas duas primeiras fases do jogo, ficando a terceira fase mais voltada para a compreensão da água como recurso hídrico.

Tabela 1: Conteúdos de Química identificados nas cartas verdes

\begin{tabular}{|c|c|c|c|}
\hline \multicolumn{4}{|c|}{ CARTAS VERDES } \\
\hline CONTEÚDOS & $\begin{array}{c}\text { Fase } 1 \\
\text { (19 perguntas) }\end{array}$ & $\begin{array}{c}\text { Fase } 2 \\
\text { (14 perguntas) }\end{array}$ & $\begin{array}{c}\text { Fase } 3 \\
\text { (12 perguntas) }\end{array}$ \\
\hline Propriedades da Matéria & 10 & 1 & - \\
\hline Mistura & - & 5 & 2 \\
\hline Solubilidade & 1 & 2 & 1 \\
\hline Ligação química & 1 & 1 & - \\
\hline Forças intermoleculares & 1 & - & - \\
\hline Funções Inorgânicas & 1 & 3 & - \\
\hline Cinética & 1 & - & - \\
\hline Propriedade Coligativa & 2 & 1 & 2 \\
\hline Ácido /base & - & 1 & 1 \\
\hline Termoquímica & 1 & 1 & - \\
\hline Óxido-Redução & - & 1 & - \\
\hline Estequiometria & 1 & - & 1 \\
\hline
\end{tabular}

Em relação às cartas vermelhas, estes conteúdos aparecem apenas na primeira fase, sendo necessários conhecimentos sobre Solubilidade (4), Forças Intermoleculares (2), Propriedade Física (4) e Tensão Superficial (1). Outra característica é que as três fases têm níveis de dificuldade crescente.

Observamos, nestas fases, que os conteúdos não estão organizados da mesma maneira que a tradicional organização curricular utilizada nas escolas e apresentada nos 
livros didáticos. A primeira fase, por exemplo, tem conteúdos que são tradicionalmente trabalhados na $1^{\mathrm{a}}$. série (cinco primeiros conteúdos da Tabela 1 ) e conteúdos da $2^{\mathrm{a}}$. ou $3^{\text {a }}$. séries. Se por um lado, isto aponta para não linearidade de conteúdos dentro do jogo, por outro lado impede que este seja utilizado por qualquer série, sendo, portanto, recomendado para alunos nas séries finais do Ensino Médio, embora o jogo permita que se joguem cada uma das fases independentemente.

\section{Categorias de Análise}

Da leitura das cartas emergiram as seguintes categorias: Química; Educação Ambiental; Química e Cotidiano; Química e Meio Ambiente e Química e CTS identificadas nas cartas do jogo. A tabela 2 apresenta a distribuição destas categorias nas cartas.

Tabela 2: Categorias identificadas nos conteúdos das cartas

\begin{tabular}{l|c|c}
\hline Categoria & Cartas Verdes = 45 & Cartas Vermelhas = 31 \\
\hline Química & 23 & 4 \\
\hline Educação Ambiental & 4 & 14 \\
\hline Química e Cotidiano & 4 & 4 \\
\hline Química e Meio Ambiente & 2 & 5 \\
\hline Química e CTS & 12 & 4 \\
\hline
\end{tabular}

Das 76 cartas 36\% apresentam conteúdos de Química, propriamente dito, que não se articulam com outras áreas de conhecimento. O mesmo é observado nos conteúdos das cartas referentes a categoria Educação Ambiental (24\%). O restante são cartas onde o conteúdo de Química está contextualizado e/ou se articula com outras áreas de conhecimento e situações socioambientais.

Destacamos que na dinâmica do jogo o estudante não tem, em uma mesma partida, acesso a todas as cartas, já que as cartas surgem aleatoriamente, à medida que a roleta é acionada. A seguir será feita uma análise de cada uma das categorias identificadas.

\section{Química}

Nesta categoria, nas cartas verdes e vermelhas, enquadram-se aquelas questões/informações em que a preocupação é somente com o conhecimento de Química. 
A fervura transforma a água líquida em vapor de água (estado gasoso), que se mistura com o ar e não é visto. O que se vê e que se parece com uma "nuvem" é, na realidade, formado de gotículas de água em estado líquido, e não de vapor. Com base nessas informações, como se denomina a temperatura na qual ocorre a passagem do estado líquido para o estado gasoso? (carta verde)

A estrutura da água apresenta carga negativa no átomo de oxigênio e carga positiva nos átomos de hidrogênio. Estas pequenas cargas da molécula da água possibilitam, através da ligação de hidrogênio sua associação a outras moléculas de água formando uma rede. (carta vermelha).

Desta forma, as questões reproduzem a forma tradicional de ensinoaprendizagem de Ciências, marcada pela "manutenção do conteudismo típico" desta relação. (BRASIL, 2002 p.105)

\section{Educação Ambiental}

Foram enquadradas nesta categoria, aquelas cartas cujo conteúdo está relacionado com a transmissão de conhecimento sobre uso, distribuição e preservação do recurso hídrico. A maior parte está presente nas cartas vermelhas.

Ao deixar uma torneira aberta, o gasto da água pode chegar a aproximadamente 30.000 litros por dia. Deixando-se uma torneira pingar por um determinado tempo, haveria um gasto considerável? (carta verde)

A crise atual de água atingiu muitas regiões do planeta. Um terço da população mundial habita áreas com estresse de água. 1,3 bilhões de pessoas não têm acesso à água potável e 2 bilhões não têm acesso à saneamento adequado. $70 \%$ das retiradas de água são utilizadas para irrigação (carta vermelha).

Nessa categoria predominam questões/informações que valorizam apenas os aspectos cognitivos do conhecimento sobre a problemática da água, reproduzindo uma prática conservacionista de Educação Ambiental. Nesta perspectiva, acredita-se que "transmitindo o conhecimento correto fará com que o indivíduo compreenda a problemática ambiental e que isso vá transformar seu comportamento e a sociedade" (GUIMARÃES, 2004, p.27)

\section{Química e Cotidiano}

Nesta categoria encontram-se as questões que articulam o conhecimento de química com situações do cotidiano:

Quando falamos em água, pensamos na água que bebemos, que usamos para fazer comida, para tomar banho ou para lavar roupa. Mas, também encontramos a água nas geleiras e no gelo que você retira do congelador, formando nuvens, e evaporando de uma chaleira no fogão quando alguém prepara um café. No ambiente a água pode ser encontrada em quais estados físicos? (carta verde) 
A presença de sais dissolvidos de cálcio, magnésio e sulfatos caracterizam a água como água dura. Embora não ocasione problemas de saúde, não deixa que a mesma forme espuma com o sabão e pode causar incrustações nas tubulações. (carta vermelha).

Assim, o conhecimento escolar é conduzido de forma a "viabilizar o domínio do conhecimento cientí co sistematizado na educação formal, reconhecendo sua relação com o cotidiano e as possibilidades do uso dos conhecimentos apreendidos em situações diferenciadas da vida" (BRASIL, 2002 p.18).

\section{Química e Meio Ambiente}

A inserção do tema no jogo é aqui conduzida pela apresentação de aspectos e impactos ambientais, de modo a favorecer a compreensão de fenômenos químicos e físicos em um ambiente natural. Pela própria característica da temática ambiental, algumas destas questões são interdisciplinares, perpassando por conceitos da Biologia e da Geografia.

Nas águas de rios, normalmente, se encontram argilas dispersas, que sofrem coagulação e precipitação no delta dos rios quando encontram a água do mar que contém sais dissolvidos, como cloreto de sódio. A formação de ilhas fluvias se dá por esse processo de precipitação do material carreado dos rios. Qual o papel dos íns $\mathrm{Na}^{+}$e $\mathrm{Cl}^{-}$na precipitação? (carta verde).

Nas metrópoles, a temperatura é normalmente mais elevada. Com o aquecimento as partículas de ar deslocam-se com maior rapidez para as camadas mais altas e carregam a umidade da brisa. Ao entrar em contato com as temperaturas mais frias, há condensação das partículas e fortes chuvas. Esse fenômeno que ocorre principalmente nos meses de verão e está relacionado com as enchentes, é chamado de "ilhas de calor". (carta vermelha)

Esta categoria vai ao encontro das propostas estabelecidas nos PCN de Ciências da Natureza e suas Tecnologias (BRASIL, 2002), já que procura explorar as relações entre o conhecimento científico e o entendimento de processos naturais e antrópicos.

\section{Química e CTS}

De acordo com Hofstein et al (1988 apud SANTOS e SCHNETZLER, 2003 p.59):

CTS significa o ensino de conteúdo de ciência no contexto autêntico do seu meio tecnológico e social. Os estudantes tendem a integrar a sua compreensão pessoal do mundo natural (conteúdo da ciência) com o mundo construído pelo homem (tecnologia) e o seu mundo social do dia a dia (sociedade). 
Esta é a terceira categoria que mais aparece no jogo (21\%) e, alguma das perguntas além de relacionar o conteúdo de química perpassa por outras áreas de conhecimento, característica das propostas em CTS (AULER e DELIZOICOV, 2001; AULER e BAZZO, 2001).

Em regiões do mundo em que a água é escassa, como em Israel e em alguns países árabes retira-se o excesso do sal da água do mar de modo que ela possa servir para consumo doméstico, industrial e na agricultura. Esse processo é chamado de: (carta verde).

Um dos principais efeitos da eutrofização dos ecossistemas aquáticos é a mortalidade de peixes associada à ausência de oxigênio dissolvido produzida pelo extenso florescimento de cianobactérias e aumento da matéria orgânica em decomposição. Isso produz uma série de impactos econômicos tais como: aumento dos custos de tratamento, perda do valor estético dos ecossistemas aquáticos e diminuição do valor turístico devido ao impedimento a navegação e a recreação. (carta vermelha).

\section{CONSIDERAÇÕES FINAIS}

$\mathrm{Na}$ análise do conteúdo do jogo das águas foi identificado que embora a temática água permita o desenvolvimento dos conteúdos de química articulado com questões cotidianas, tecnológicos e socioambientais, os conceitos puramente químicos têm forte apelo dentro do jogo, representando $36 \%$ do total de cartas. As cartas que foram classificadas como Educação Ambiental, também possuem textos que não implicam em conhecimentos da Química sendo constituídas de enfoques informativos. Isto pode sugerir a intenção dos autores de reforçar os conteúdos de química aprendidos em sala de aula e ampliar o conhecimento sobre o recurso hídrico; sua distribuição geográfica, aspectos sociais, econômicos e impactos ambientais. Essa pode, inclusive, ser uma proposta de utilização do jogo pelo professor, que não pode desconsiderar o seu papel como mediador do processo ensino aprendizagem apropriando-se das questões que, a princípio trazem um aspecto informativo, em ponto de debates e reflexões.

Nas outra três categorias os conteúdos de Química aparecem nas cartas articulado com outras áreas de conhecimento, destacando o cotidiano, as interações ambientais e sua relação com a tecnologia e a sociedade. Esta articulação permite que o professor introduza novas linguagens no ensino de química favorecendo o aprendizado de química de forma integrada.

\section{REFERÊNCIAS BIBLIOGRÁFICAS}

AULER,D. e BAZZO, W.A. Reflexões para a implementação do movimento CTS no contexto educacional brasileiro. Ciência e Educação. Bauru. v.7, n.1, p1-13, 2001. 
e DELIZOICOV, D. Alfabetização Científico-Teconológica Para Quê? Ensaio. Pesquisa em Educação em Ciências, v.3, n. 2, p.105-116, 2001.

BRASIL Banco Internacional de Objetos Educacionais. MEC/MCT, 2008. Disponível em http://objetoseducacionais2.mec.gov.br/. Acesso em 07/02/2012

BRASIL Ciências da natureza, matemática e suas tecnologias / Secretaria de Educação Básica. - Brasília : Ministério da Educação, Secretaria de Educação Básica, 2006. 135 p. (Orientações curriculares para o ensino médio; volume 2)

BRASIL. PCN + Ensino médio: orientações educacionais complementares aos Parâmetros Curriculares Nacionais - Ciências da Natureza, Matemática e suas Tecnologias. Ministério da Educação (MEC), Secretaria de Educação Média e Tecnológica. Brasília: MEC/Semtec, 2002

GUIMARÃES, M. e VASCONCELLOS, M. M. Relações entre educação ambiental e educação em ciências na complementaridade dos espaços formais e não formais de educação. Educar em Revista. [online]. n.27, pp. 147-162. Editora UFPR. 2006.

GUIMARÃES, M. Educação Ambiental Crítica. In: Identidades da educação ambiental brasileira / Ministério do Meio Ambiente. Diretoria de Educação Ambiental. Philippe Pomier Layrargues (coord.). 2004. Disponível em: http://www.usp.br/pure/scc/upload/identidades\%20da\%20educa\%E7\%E3o\%20ambient al\%20br.pdf,

KISHIMOTO, T. M. (Org). O Brincar e suas teorias. São Paulo: Pioneira Thomson Learning, 2002.

KRASLCHIK, M. Reformas e Realidade: o caso do ensino das ciências. São Paulo Perspectivas. V.14 N.1 Jan./Mar. 2000.

LÜDKE, M. e ANDRÉ, M. E. D. A. Pesquisa em educação: abordagens qualitativas. São Paulo: EPU, 1986.

MORAES, R.Uma tempestade de luz: A compreensão possibilitada pela análise textual discursiva. Ciência e Educação. Bauru. v.9, n.2, p191-211, 2003.

OLIVEIRA, A.S. e SOARES, M.H.F.B. Júri químico - atividade lúdica para discutir conceitos de química. Química Nova na Escola, n.21, p.18-24, 2005

SANTOS, W. e SCHNETZLER, R.P. Educação em Química: Compromisso com a cidadania. $3^{\mathrm{a}}$ ed. Ijuí: Ed. Unijuí, 2003.

SCHNETZLER, R.P. A Pesquisa no Ensino de Química e a Importância da Química Nova na Escola. Revista Química Nova na Escola, N. 20, p.49-54, Nov., 2004.

SCHNETZLER, R.P. Apontamentos Sobre a História do Ensino de Química no Brasil. In: SANTOS, W.L.P. MALDANER, O.A. (Orgs.). Ensino de Química em Foco. Ijuí:Ed. Unijuí, 2010 
SOARES, M.H.F.B. e CAVALHEIRO, E.T.G. O ludo como um jogo para discutir conceitos em termoquímica. Química Nova na Escola, n. 23, p.27-31, 2006

VYGOTSKY, Lev. S. Psicologia Pedagógica - edição comentada. Porto Alegre:

Artmed, 2003. 